\title{
V. On the true composition of chlorindatmit
}

\section{August Wilhelm Hofmann Ph.D.}

To cite this article: August Wilhelm Hofmann Ph.D. (1845) V. On the true composition of chlorindatmit , Philosophical Magazine Series 3, 27:177, 20-23, DOI: 10.1080/14786444508645217

To link to this article: http://dx.doi.org/10.1080/14786444508645217

$$
\text { 曲 Published online: } 30 \text { Apr } 2009 .
$$

Submit your article to this journal ๘

Џلl Article views: 2 


\section{Dr. Hofmann on the true Composition of Chlorindatmit.}

Copper duplicates of steel or copper engravings, it is well known, are not nearly so durable as the original plates, yet in some cases they may be advantageously employed, - not however where very large numbers are likely to be required, as, for example, in the printing of bank notes. I was once consulted as to the practicability of coating the interior of the air-pumps and the valve facings of large marine engines by the electro-metallurgic process, and I include this as one of the improper applications of the art. In conclusion, I again repeat, that the processes of electro-metallurgy are a valuable acquisition to the arts, yet it is necessary to bear in mind its defects, in order that we may not apply it to purposes for which it is unfitted.

\section{On the true Composition of Chlorindatmit.}

By August: Wilhelm Hofmann, Ph.D.*

$\mathrm{N}$ a preceding memoir on the Metamorphoses of Indigo, I I have described under the name of trichloraniline a body which may be regarded as aniline, in which three equivalents of hydrogen are replaced by an equal number of chlorine:

$$
\begin{aligned}
& \text { Aniline . }=\mathrm{C}_{12} \mathrm{H}_{7} \mathrm{~N} \\
& \text { Trichloraniline . }=\mathrm{C}_{12}\left\{\begin{array}{l}
\mathrm{H}_{4} \\
\mathrm{Cl}_{3}
\end{array}\right\} \mathrm{N} .
\end{aligned}
$$

I had already, a year and a half ago, observed the formation of this body by the action of chlorine on aniline $\dagger$, but at that time the quantity obtained was so small that I was obliged to content myself with a conjectural opinion of its constitution. More lately I found that the same substance was produced by the treatment of chloraniline with chlorine. Even by the last-mentioned way the quantity obtained was but small. With all my efforts I could not obtain more than was just sufficient for one combustion, which unfortunately gave somewhat too much carbon $\ddagger$. Although myself thoroughly convinced of the exactness of the given formula, the method of formation of this body, the complete analogy with tribromaniline and chlorodibromaniline, independently of the analysis adduced, being sufficient evidences,-I thought it however desirable to place the composition of trichloraniline beyond every doubt by the production of better numbers.

At first $I$ thought of obtaining these numbers by a repeti-

* Communicated by the Chemical Society; having been read February $17,1845$.

+ Liebig's Ann. vol. xlvii. p. 68, and Phil. Mag. S. 3. vol. xxvi. p. 199.

$\ddagger$ See the preceding Memoir. 
tion of the preparation and analysis, until I found the object could be attained by a much more convenient way.

For this purpose I must here mention some results obtained by Erdmann in his excellent investigation on indigo.

If indigo suspended in water be treated with chlorine, it is transformed, as is known, into a reddish yellow mass, which is a mixture of different substances. On submitting this to distillation with water, chlorisatine and dichlorisatine remain in the retort, whilst another body volatilizes with the watery vapour, which according to Erdmann contained no nitrogen. He called this substance chlorindoptene*, and gave for it the following formula:

$$
\mathrm{C}_{32} \mathrm{H}_{8} \mathrm{Cl}_{8} \mathrm{O}_{4} \text {. }
$$

By later experiments Erdmann found however that on distilling chlorindoptene with potash or carbonate of potash it is decomposed into a neutral body which passes over, and an acid which remains in the retort united to the potash. The latter is chlorindoptenic acid (chlorophenisic acid of Laurent); the former Erdmann called chlorindatmit, and gave it the formula $\mathrm{C}_{12} \mathrm{H}_{4} \mathrm{Cl}_{3} \mathrm{O}_{2}$.

Whence comes this body? In what relation does it stand to the other members of the indigo or phenyle series? Among the many derivatives of indigo made known to us by the investigations of Erdmann and Laurent it stands quite isolated.

On comparing the properties which Erdmann described as belonging to chlorindatmit with those I had observed in trichloraniline, it appeared to me in the highest degree probable that these bodies were identical. The properties of both bodies correspond exactly, and the method of formation is extremely alike. The production of trichloraniline, as well as that of chlorindatmit, is accompanied by the formation of chlorindoptenic acid. Erdmann had determined the carbon, hydrogen and chlorine in chlorindatmit. His numbers correspond completely with the composition of trichloraniline. For comparison I placed together the theoretical numbers of this body and the analytical results of Erdmann.

Chlorindatmit.

$$
\begin{aligned}
& \text { Carbon } \cdot:=36 \cdot 42 \dagger \\
& \text { Hydrogen }:=2 \cdot 23 \\
& \text { Chlorine . } \cdot=53.58 \\
& \text { Loss } \cdot . \quad \cdot=\frac{7 \cdot 79}{100 \cdot 00}
\end{aligned}
$$

Trichloraniline.

Carbon,$\quad=36 \cdot 66$

Hydrogen.$=2.03$

Chlorine ..$=54.09$

Nitrogen $\cdot=\frac{7 \cdot 22}{100 \cdot 00}$

* Journ, für Pralt. Chem., vol. xix. p. 334.

$\uparrow$ The equivalent of carbon is here taken as 75 . 
Erdmann did not look for nitrogen in chlorindatmit as he had found none in chlorindoptene. Did chlorindoptene consist of equal equivalents of chlorindoptenic acid and chlorindatmit, such a compound (assuming chlorindatmit to be an azotized body) would contain 3.61 per cent. nitrogen, a quantity which could not have been overlooked. It is, however, not composed of a like quantity of each element, but the chlorindoptenic acid predominates very much, so that the amount of nitrogen is much reduced, and may be easily overlooked. On the other hand, the proportion of carbon and hydrogen cannot essentially alter, as chlorindoptenic acid and chlorindatmit contain nearly equal quantities.

To determine this question by experiment, I treated with chlorine, according to Erdmann's method, a quarter of a pound of reduced and again oxidized indigo suspended in water. Although the operation was conducted in sunshine, yet it was only after three or four days that the indigo was converted into the brownish-yellow body. The whole mass, together with the fluid, was poured into a retort and distilled over an open fire. In the receiver a yellow crystalline substance condensed and swam on the surface of the water, which had also passed over and contained hydrochloric acid. The distilled product was saturated with potash ley, which communicates a dark colour to the fluid from the solution of a portion of the crystals, and the whole was again submitted to distillation. By gently warming the retort, a vapour was evolved which condensed in the neck in the form of fine white crystals like hairs, about an inch long, which, on bringing the fluid to the boiling-point, passed over with the watery vapours as an oil and again crystallized in the receiver. The crystals were separated by filtration and dried. The investigation was confined to the single question, whether chlorindatmit so prepared contained nitrogen or not?

On passing the vapour of chlorindatmit over fused potassium a large quantity of cyanide of potassium was formed, which evolved freely hydrocyanic acid on the addition of an acid. A mixture of a proto- and persalt of iron produced a gray-brown precipitate, which assumed the pure colour of Berlin blue by the addition of a little hydrochloric acid. Further, on heating with the soda-lime mixture a quantity of ammonia was given off. Chlorindatmit therefore contains nitrogen.

From the preceding facts several conclusions may be drawn.

1st. The body produced by the action of chlorine on ani- 
line and chloraniline has in reality the following composition:

$$
\mathrm{C}_{12}\left\{\begin{array}{l}
\mathrm{H}_{4} \\
\mathrm{Cl}_{3}
\end{array}\right\} \mathrm{N} \text {. }
$$

2nd. The chlorindatmit of Erdmann is nothing but trichloraniline.

3rd. The name chlorindoptene merely denotes an indefinite mix ture of chlorindoptenic acid and trichloraniline.

The formation of trichloraniline by the action of chlorine on indigo is not at all surprising. The transformation of indigo into nitropicric and chlorindoptenic acids, and into aniline, proves sufficiently that there are present in this body the conditions necessary for the production of all the members of the phenyle series. The action of potash and of chlorine on indigo is in this respect essentially the same. 'The only difference is, that in the first instance a pure product of oxidation is obtained, whilst in the second a number of the hydrogen equivalents of this pioduct is replaced by a corresponding number of the oxidlizing agent, viz. chlorine. In the one case aviline is formed, in the other trichloraniline. The latest investigations of Cahours*, in which he succeeded in obtaining salicylic acid by treating indigo with hydrate of potash, show that out of this latter substance hydrate of phenyle can likewise be produced, the compound free from chlorine, which corresponds to chlorindoptenic acid.

In an analogous manner Erdmann t obtained, by the action of bromine on indigo, bromisatine, dibromisatine and bromindoptene. This last substance, distilled with potash, is decomposed into bromindoptenic acid and bromindatmit. Erdmann did not analyse bromindatmit; but it is scarcely necessary to remark that this body is nothing but tribromaniline(Fritzsche's bromaniloid),

$$
\mathrm{C}_{12}\left\{\begin{array}{l}
\mathrm{H}_{4} \\
\mathrm{Br}_{3}
\end{array}\right\} \mathrm{N} \text {. }
$$

VI. Analyses of Farm-Yard Manure, and of Coal-Gas. By 'Thomas Richandson, Esq. $\ddagger$

THE accompanying analysis of farm-yard manure is part of an investigation in which $I$ am at present engaged, and the results show, rather unexpectedly, that this manure has a somewhat similar composition in different localities.

* Compt. Rend.

$\dagger$ Journ. für Prakt. Cheml, vol. xix. p. 358.

+ Communicated by the Chemical Society; having been read February 17,1845 . 